\title{
ANALISIS WEBSITE WIKI VERSAILLUS DENGAN MENGGUNAKAN METODE PIECES
}

\author{
Analysis of Wiki Versaillus Website Using Pieces Method \\ I Ketut Sudaryana ${ }^{1)}$, Hadi Sanjaya ${ }^{2)}$ dan Ricky Tjong ${ }^{3)}$ \\ 1) Program Studi Teknik Informatika, STMIK Widuri, Jakarta \\ ${ }^{2,3)}$ Program Studi Sistem Informasi, Universitas Bunda Mulia, Jakarta
}

Diterima 10 Agustus 2019 / Disetujui 22 Agustus 2019

\begin{abstract}
The development of this age in the world is characterized by information technology. For a long time, humans can not be separated from technology. The development of Internet information technology effected the creation of the internet. The Internet sends people to communicate and search for information about anyone. How to find existing information is to open websites that exist on the internet. Website is a system where information in the form of text, images, sound, and others are presented in hypertext form. One of the websites that contain information is Versaillus. Versaillus is a website that contains information about a game called Mobile Legends and the manifold of Versaillus is a wiki's site, but the website is not crowded by people. Therefore, the author will researching the site versaillus by using PIECES method. The results of this study can change the site versaillus to be better and better from PIECES method.
\end{abstract}

Keywords: PIECES, Internet, Information Technology, Versaillus

\begin{abstract}
ABSTRAK
Perkembangan zaman di dunia ini ditandai dengan perkembangan teknologi informasi. Semakin lama, manusia tidak dapat terlepas dari teknologi. Perkembangan teknologi informasi mengakibatkan terciptanya internet. Internet digunakan jutaan orang untuk berkomunikasi dan mencari informasi yang ada tentang apapun di dunia ini. Cara mencari informasi yang ada adalah dengan membuka website-website yang ada di internet. Website merupakan sebuah sistem yang memberikan informasi dalam bentuk teks, gambar, video, suara, dan lain-lainnya dituliskan dalam bentuk hypertext. Salah satu website yang berisikan informasi yaitu Versaillus. Versaillus merupakan sebuah website yang berisi informasi tentang sebuah game bernama Mobile Legends dan berjenis website wiki, akan tetapi website tersebut belum ramai dikunjungi orang. Oleh karena itu, penulis akan meneliti website Versaillus dengan menggunakan metode PIECES. Penulis berharap hasil dari penelitian ini dapat mengubah website Versaillus menjadi lebih baik dan agar mengetahui kelemahan dan kekuatan yang dimiliki Versaillus dari metode PIECES.
\end{abstract}

Kata Kunci: Website, PIECES, Internet, Teknologi Informasi, Versaillus

\footnotetext{
*Korespondensi Penulis:

E-mail: ketutbali2010@gmail.com
} 


\section{PENDAHULUAN}

Pada saat ini, teknologi merupakan suatu hal yang sangat dibutuhkan oleh masyarakat. Beberapa merk dari teknologi terkenal sedang berlomba-lomba untuk menciptakan sebuah teknologi terobosan terbaru dan tercanggih. Teknologi informasi (TI) merupakan kontributor penting bagi kesuksesan ekonomi (Andry, 2016). Aplikasi yang ada pada teknologi sekarang ini kebanyakan membutuhkan internet. Dengan adanya internet, informasi sangat mudah didapatkan. Akan tetapi, internet membutuhkan aplikasi pula untuk mencari informasi tersebut (Nugroho, 2016). Internet membutuhkan browser untuk mencari sumber-sumber informasi yang ada. salah satunya adalah Versaillus. Website merupakan kumpulan halaman-halaman yang berisi informasi yang disimpan diinternet yang bisa diakses atau dilihat melalui jaringan internet pada perangkat-perangkat yang bisa mengakses internet itu sendiri seperti komputer. Definisi kata web adalah Web sebenarnya penyederhanaan dari sebuah istilah dalam dunia komputer yaitu WORLD WIDE WEB yang merupakan bagian dari teknologi Internet (Andarwati, dan Sankarto, 2005). Versaillus merupakan sebuah web yang berisi informasi tentang sebuah game berjudul Mobile Legends. Versaillus merupakan jenis website bertipe wiki. Seperti Wikipedia, versaillus menampilkan informasiinformasi tentang game tersebut. Wiki merupakan jenis website yang menampilkan informasi-informasi seperti wikipedia, akan tetapi jenis web ini memungkinkan pembaca untuk mengedit dan menambahkan sendiri informasi yang ingin ditambahkan di web tersebut. Meskipun pembaca dapat mengedit dan menambahkan informasi, web jenis ini tetap menyediakan admin untuk mengecek apakah informasi yang ditambahkan pembaca tersebut sesuai atau tidak (Hastanti, dkk, 2013). Pada penelitian kali ini, penulis akan menggunakan metode PIECES. Metode PIECES merupakan kerangka kerja yang digunakan untuk klasifikasi permasalahan yang ada berdasarkan kategori yang disebutkan dalam tiap hurufnya Performance, Information, Economic, Control, Efficiency, Service (Whitten \& Bentley, 2007). Ada beberapa tujuan dari dilakukannya penelitian ini. Untuk pembaca, ditujukan untuk mendapatkan informasi yang lebih lengkap dan berguna untuk keperluan masing-masing. Untuk pemilik web Versaillus, ditujukan agar web Versaillus lebih banyak dikunjungi dan dibutuhkan pembaca untuk mendapatkan informasi. Untuk penulis, ditujukan agar penulis mendapatkan kelemahan dan kekuatan web tersebut. Penulis melakukan penelitian mencakup proses-proses yang terdapat pada website tersebut, mulai dari penambahan informasi, penambahan data, dll. Cara peneliti mengetahui kelemahan dan kekuatan web Versaillus adalah dengan menggunakan metode PIECES. Sebelumnya, peneliti telah mencari jurnal-jurnal dan metode-metode yang cocok untuk melakukan penelitian ini. Penulis melakukan studi literatur terhadap jurnal-jurnal dan metode yang telah didapat. Hasilnya, peneliti menetapkan metode yang akan digunakan untuk meneliti web Versaillus dengan menggunakan metode PIECES.

\section{TINJAUAN PUSTAKA}

Setelah melakukan pembelajaran penelitian sebelumnya, penulis memilih jurnal yang berjudul Analisis dan Evaluasi Kepuasan Pengguna Sistem Informasi Perpustakaan Dengan Menggunakan PIECES Framework yang dibuat oleh Adi Supriyatna untuk dibahas. Jurnal ini dipilih penulis dikarenakan tema yang hampir sama dengan penelitian penulis sekarang ini. Adapun kelebihan yang dimiliki jurnal tersebut, yaitu hasil dan pembahasan yang ada pada jurnal tersebut sudah sangat jelas, dimulai dari performance, Information, dst. Semua penjelasan mengenai PIECES tersebut sudah sangat rinci. Hasil yang didapat dari jurnal tersebut adalah Sistem informasi perpustakaan berdasarkan kerangka kerja PIECES sudah mampu memberikan kepuasan kepada 
pengguna. Metode PIECES dapat digunakan untuk menganalisa tingkat kepuasan pengguna atas sistem informasi yang digunakan (Adiguna, dkk, 2015).

Penelitian sebelumnya oleh Moch Farid Fauzi, (2017) yang berjudul Rancang Sistem Direktori Berkas Arsip Siswa Sekolah Dasar, Penelitian ini menghasilkan Prototype System perancangan Sistem Direktori Siswa yang dapat digunakan untuk mempermudah kinerja Wali Kelas dan karyawan tata Usaha dalam proses pelayanan dan pengelolaan berkas arsip siswa pada jenjang Sekolah Dasar. Penelitian ini menggunakan metode PIECES (Supriyatna, 2015).

Penelitian selanjutnya milik Alfie Nur Rahmi, (2017) yang berjudul Analisis PIECES Sistem Tracer Study Online Berbasis Website di Universitas AMIKOM Yogyakarta, penelitian ini menghasilkan informasi yang dihasilkan dari tracer online belum relevan dengan kebutuhan DIKTI, BPC dan alumni dikarenakan isi pertanyaan tracer yang tidak pernah di update padahal DIKTI telah mengumumkan bentuk form tracer study terbaru pada tahun 2012 (Farid, 2017).

\section{A. Analisis}

Menurut Kamus Besar Bahasa Indonesia, Analisis memiliki arti sebagai berikut (KBBI, 2018): Penyelidikan suatu masalah / peristiwa, untuk mencari kebenarannya. Pembuatan kesimpulan terhadap bagiannya dan pengambilan bagiannya sendiri serta relasi terhadap bagian-bagiannya untuk mendapatkan pengertian yang tepat dan memahami isi kesimpulan tsb. Penjabaran sesudah dikaji sebaik-baiknya

\section{B. Website}

Website adalah suatu halaman yang menampilkan konten, gambar, video, dan lain-lain yang hanya dapat diakses ketika menggunakan internet. Sebuah Website mempunyai halaman awal, yaitu halaman yang pertama kali tampil apabila kita membuka alamat pada internet, halaman pertama ini biasa disebut homepage. Website biasanya digunakan untuk menampilkan berbagai informasi yang ada di dunia dan menampilkan apa saja yang ingin ditampilkan oleh pemiliknya. Jenis website ada bermacam-macam, ada Blog, Wiki, web portal, E-commerce, Forum, dan lain-lain. Walaupun mempunyai banyak jenis, website tetap disebut sebagai sarana informasi komunikasi (Dunia online, 2018).

\section{Wiki}

Website jenis wiki yang paling sering digunakan oleh masyarakat sekarang adalah wikipedia. Website Wiki adalah halaman yang mengizinkan pengunjung untuk ikut mengedit dan menambahkan data dan informasi yang ada di halaman tersebut dengan beberapa peraturan yang ada. Setiap website jenis ini memiliki peraturan yang berbeda-beda. Meskipun pengunjung dapat mengubah dan menambahkan informasi, ada sekolompok orang yang bertugas untuk memeriksa apakah informasi yang ditambahkan pengunjung tersebut layak atau tidak. Meskipun website wiki ini sering dijadikan refrensi, informasinya belum bisa 100\% dipercaya (Husni, 2008).

\section{PIECES}

Beberapa penjelasan tentang PIECES (Yunus, 2009) yaitu:

Analisis Kinerja (Performance), sangat berkaitan dengan peningkatan terhadap kinerja (hasil kerja) sistem yang baru sehingga menjadi lebih efektif. Kinerja dapat diukur dari banyaknya volume pekerjaan yang dilakukan dalam satuan waktu, dan waktu yang digunakan untuk menyelesaikan perubahan pekerjaan yang terjadi, dalam hal ini adalah jumlah pelayanan administrasi Desa yang diberikan kepada masyarakat dalam satuan waktu yang telah ditentukan.

Analisis Informasi (Information), dalam penyajian informasi sering terjadi 
keterlambatan, bahkan kesalahan-kesalahan informasi yang dihasilkan sering tidak dapat langsung digunakan sebagai dasar pengambilan keputusan, oleh sebab itu diharapkan adanya informasi yang akurat, tepat waktu dan relevan

Analisis Ekonomi (Economy), persoalan ekonomi berkaitan dengan masalah biaya dan manfaat. Dengan adanya kelemahankelemahan yang ada pada sistem yang lama maka akan mungkin terjadi biaya yang tidak dapat diramal atau dikenal. Pengembangan sistem diharapkan dapat memberikan banyak manfaat dan ketidakeffisienan biaya yang terjadi bisa diminimalisasi sekecil mungkin. Dalam pembuatan laporan, sistem yang manual menyebabkan tingkat kesalahan tinggi sehingga membutuhkan banyak biaya.

Analisis Pengendalian (Control), kontrol atau pengendalian dalam sebuah sistem sangat diperlukan yaitu untuk menghindari dan mendeteksi secara dini terhadap kesalahankesalahan yang terjadi serta untuk menjamin keamanan data atau informasi. Dengan adanya pengendalian maka tugas-tugas atau kinerja yang mengalami gangguan bisa diatasi

Analisis Efisiensi (Efficiency), dengan adanya analisis ini ada upaya untuk meningkatkan efisiensi dalam operasional dengan menggunakan sumber daya yang tersedia. Efisiensi ini erat hubungannya dengan input yaitu bagaimana sumber data yang ada dapat digunakan seminimal mungkin sehingga tidak terjadi pemborosan. Tidak dapat dipungkiri lagi kalau tingkat ketelitian dan kemampuan manusia cukup terbatas sedangkan pengolahan data dan laporan masih mengandalkan pada kemampuan manusia.

Analisis Pelayanan (Service), peningkatan terhadap pelayanan yang diberikan oleh sistem berhubungan dengan kepuasan dari user, dan juga kepuasan dari masyarakat yang mendapat pelayanan. Pelayanan dari segi informasi mempunyai sasaran baik bagi pihak pemerintah, pegawai maupun masyarakat yang membutuhkan. Koordinasi yang belum teratur mengenai pengolahan data, penyimpanan laporan serta dokumentasi akan menurunkan kualitas pelayanan yang pada akhirnya akan mengakibatkan kerja dari bagian tersebut menjadi terganggu sehingga pelayanan perlu ditingkatkan.

\section{METODE PENELITIAN}

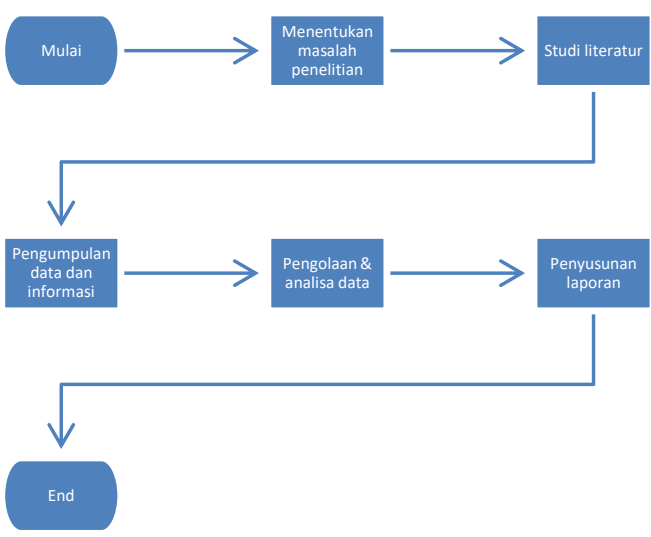

Gambar 1 Metode Penelitian

\section{A. Menentukan masalah penelitian}

Pada tahap ini, penulis menentukan masalahmasalah yang ada pada website yang ingin diteliti.

\section{B. Melakukan studi literatur}

Penulis mulai mencari jurnal-jurnal yang berkaitan dengan penelitian ini. Data yang telah didapat dari studi ini nantinya akan digunakan sebagai acuan untuk membuat penelitian

\section{Pengumpulan data dan informasi}

Pengumpulan data dan informasi dilakukan untuk mendapatkan data dan informasi yang akan digunakan untuk diteliti. Data dan informasi dari website ini berupa file php, database, html, dll.

\section{Pengelolahan dan analisis data penelitian}

Pengolahan dan analisis data yang telah didapat oleh penulis akan dilakukan setelah terkumpulnya data dan informasi. Penulis mulai mengelola informasi yang didalam 
disebuah komputer dan menganalisis datadata yang didapat.

\section{E. Menyimpulkan hasil penelitian}

Penyimpulan hasil penelitian dilakukan oleh peneliti atas informasi dan data yang telah dikelolah.

\section{HASIL DAN PEMBAHASAN}

Peneliti telah melakukan pembelajaran dan pengamatan pada website Versaillus. Pembelajaran ini dilakukan dengan cara mengobservasi langsung terhadap web dan melakukan wawancara. Pengobservasian ini dilakukan dengan cara mengamati semua tombol, data, informasi, dll. yang dimiliki oleh website tersebut dan wawancara dilakukan dengan menanyakan langsung owner website. Setelah mempelajari website Versaillus, penulis telah merangkum beberapa hal berikut menggunakan metode PIECES.

\section{Tabel 1 Analisis Performance}

Tabel 2 Analisis Information

\begin{tabular}{|c|c|c|}
\hline Variabel & Analisis & $\begin{array}{l}\text { Kebutuhan } \\
\text { Kedepan }\end{array}$ \\
\hline Akurat & $\begin{array}{l}\text { Sesuai jenis website } \\
\text { Versaillus ini yang } \\
\text { berupa wiki, } \\
\text { Versaillus belum } \\
\text { dapat membuat user } \\
\text { dapat menambahkan } \\
\text { informasinya } \\
\text { sendiri. }\end{array}$ & $\begin{array}{l}\text { Membuat sistem } \\
\text { agar user dapat } \\
\text { menambahkan } \\
\text { informasi sendiri } \\
\text { dan admin yang } \\
\text { mengaturnya. }\end{array}$ \\
\hline $\begin{array}{l}\text { Relevan } \\
\text { (berguna) }\end{array}$ & $\begin{array}{lr}\text { Informasi } & \text { yang } \\
\text { diberikan } & \text { oleh } \\
\text { website } & \text { Versaillus } \\
\text { sangat berguna bagi } \\
\text { beberapa } & \text { pemain } \\
\text { game } & \text { Mobile } \\
\text { Legend. } & \end{array}$ & $\begin{array}{l}\text { Menambahkan } \\
\text { foto/video } \\
\text { tutorial, informasi } \\
\text { yang diberikan } \\
\text { sangat berguna } \\
\text { akan tetapi } \\
\text { kurangnya variasi } \\
\text { oleh web tersebut. } \\
\text { Misalnya } \\
\text { penambahan } \\
\text { video, } \\
\text { menambahkan } \\
\text { tombol, dsb. }\end{array}$ \\
\hline $\begin{array}{l}\text { Tepat } \\
\text { waktu }\end{array}$ & $\begin{array}{lr}\text { Kurangnya } & \text { update } \\
\text { yang tepat } & \text { waktu } \\
\text { pada } & \text { website } \\
\text { Versaillus. Jika ada }\end{array}$ & $\begin{array}{l}\text { Mempercepat } \\
\text { update pada } \\
\text { website } \\
\text { Versaillus, jika }\end{array}$ \\
\hline
\end{tabular}

\begin{tabular}{lr|l|}
\multicolumn{2}{l}{ update pada } & game, \\
biasanya & Versaillus \\
lama & dalam & ada update maka \\
melakukan & update. & Versaillus \\
diwajibkan untuk & meng-update \\
Butuh & waktu & pada hari itu juga \\
beberapa & waktu & agar pembaca \\
untuk & Versaillus & senang. \\
melakukan update & Kebanyakan \\
ke web tersebut. & $\begin{array}{l}\text { pembaca ingin tau } \\
\text { lebih banyak akan } \\
\text { update kedepan di } \\
\text { game tersebut. }\end{array}$ \\
\end{tabular}

Pada variable Performance ini diukur 2 macam hal, yaitu throughput dan response time. Response Time dan Throughput didapat dari mempelajari dan mewawancarai langsung pemilik website Versaillus. Berikut hasil pembelajaran pada Tabel 1 .

Pada variabel information terdapat 3 indikator yang saling mempengaruhi, diantaranya adalah sebagai berikut: akurat, relevan, dan tepat waktu. Pengukuran variabel information ini didapatkan melalui pengolahan data dari hasil wawancara yang

\begin{tabular}{|c|c|c|}
\hline Variabel & Analisis & $\begin{array}{l}\text { Kebutuhan } \\
\text { Kedepan }\end{array}$ \\
\hline $\begin{array}{l}\text { Through } \\
\text { put }\end{array}$ & $\begin{array}{l}\text { Keluaran yang } \\
\text { dihasilkan oleh } \\
\text { website Versaillus } \\
\text { sudah cukup baik } \\
\text { karena informasi } \\
\text { yang diberikan } \\
\text { sudah sangat tepat } \\
\text { tetapi informasi pada } \\
\text { website tersebut } \\
\text { masih kurang. }\end{array}$ & $\begin{array}{l}\text { Sistem baru } \\
\text { yang dirancang } \\
\text { tetap } \\
\text { memberikan } \\
\text { informasi yang } \\
\text { lebih banyak } \\
\text { mengenai } \\
\text { konten yang } \\
\text { dimiliki oleh } \\
\text { website } \\
\text { tersebut. }\end{array}$ \\
\hline $\begin{array}{l}\text { Response } \\
\text { Time }\end{array}$ & $\begin{array}{l}\text { Response Time yang } \\
\text { ada pada website } \\
\text { Versaillus ini } \\
\text { membutuhkan waktu } \\
15 \text { detik untuk ke } \\
\text { halaman } \\
\text { utama(index). Untuk } \\
\text { tombol guide, } \\
\text { dibutuhkan waktu } 50 \\
\text { detik untuk } \\
\text { membukanya. Untuk } \\
\text { tombol Informasi, } \\
\text { dibutuhkan waktu } 10 \\
\text { detik untuk } \\
\text { membukanya. }\end{array}$ & $\begin{array}{l}\text { Sistem baru } \\
\text { atau domain } \\
\text { baru yang } \\
\text { dibutuhkan } \\
\text { untuk } \\
\text { mempercepat } \\
\text { pembukaan } \\
\text { halaman } \\
\text { masing-masing } \\
\text { tombol agar } \\
\text { pengguna tidak } \\
\text { kesal menunggu } \\
\text { hal tersebut. }\end{array}$ \\
\hline
\end{tabular}

dilakukan. Wawancara yang dilaksanakan 
tersebut dilakukan dengan master admin dari website tersebut. Hasil dari pengolahan data wawancara mengenai information tersebut akan dipaparkan pada Table 2 dilaksanakan dengan melakukan wawancara dengan pemilik website.

Tabel 3 Analisis Economy

\begin{tabular}{|c|c|c|}
\hline Variabel & Analisis & $\begin{array}{l}\text { Kebutuhan } \\
\text { Kedepan }\end{array}$ \\
\hline Biaya & $\begin{array}{l}\text { Website } \\
\text { Versaillus } \\
\text { menggunakan } \\
\text { domain } \\
\text { 000.webhostapp. } \\
\text { com. Domain } \\
\text { tersebut } \\
\text { merupakan } \\
\text { sebuah domain } \\
\text { yang } \\
\text { memberikan } \\
\text { kebebasan untuk } \\
\text { kita dalam meng- } \\
\text { hosting website } \\
\text { pribadi. Bagi } \\
\text { yang meng- } \\
\text { hosting web } \\
\text { pribadi, tidak } \\
\text { akan dikenakan } \\
\text { biaya ataupun } \\
\text { gratis. }\end{array}$ & $\begin{array}{l}\text { Setelah wawancara, } \\
\text { adapun kelemahan } \\
\text { dari domain } \\
\text { 000webhostapp.com } \\
\text { tersebut, yaitu } \\
\text { seringnya website } \\
\text { akan dalam mode } \\
\text { sleep, dan selama } \\
\text { mode sleep website } \\
\text { tersebut tidak akan } \\
\text { bisa dibuka. } \\
\text { Meskipun tidak } \\
\text { dikenakan biaya, } \\
\text { banyak sekali } \\
\text { kekurangannya. } \\
\text { Pemilik website } \\
\text { dapat membeli } \\
\text { sebuah domain yang } \\
\text { lebih bagus dan baik } \\
\text { agar kualitas web } \\
\text { tersebut menjadi } \\
\text { lebih baik }\end{array}$ \\
\hline Manfaat & $\begin{array}{l}\text { Manfaat dari } \\
\text { pembuatan } \\
\text { website ini tentu } \\
\text { saja untuk } \\
\text { menambah ilmu } \\
\text { pengetahuan } \\
\text { game bagi para } \\
\text { pemain Mobile } \\
\text { Legend. Di } \\
\text { website ini, } \\
\text { pembaca } \\
\text { diberikan } \\
\text { informasi yang } \\
\text { cukup untuk } \\
\text { dibaca. }\end{array}$ & $\begin{array}{l}\text { Menambahkan } \\
\text { manfaat dari web } \\
\text { Versaillus ini, } \\
\text { bukan hanya untuk } \\
\text { pemain Mobile } \\
\text { Legends, tetapi } \\
\text { untuk seluruh } \\
\text { pengunjung. }\end{array}$ \\
\hline
\end{tabular}

Pada variabel economy terdapat 2 indikator yang saling mempengaruhi, diantaranya adalah sebagai berikut : biaya dan manfaat. Pengukuran variabel economy ini didapatkan melalui pengolahan data dari hasil wawancara yang dilakukan. Wawancara yang dilaksanakan tersebut dilakukan dengan master admin dari website tersebut. Hasil dari pengolahan data wawancara mengenai economy tersebut akan dipaparkan pada Tabel 3 dilaksanakan dengan melakukan wawancara dengan pemilik website.

Pada variabel control terdapat 1 indikator yang saling mempengaruhi, diantaranya adalah sebagai berikut: Peningkatan pengendalian system. Pengukuran variabel control ini didapatkan melalui pengolahan data dari hasil wawancara yang dilakukan. Wawancara yang dilaksanakan tersebut dilakukan dengan master admin dari website tersebut. Hasil dari pengolahan data wawancara mengenai control tersebut akan dipaparkan pada Tabel 4 dilaksanakan dengan melakukan wawancara dengan pemilik website.

Tabel 4 Analisis control 


\begin{tabular}{|c|c|c|}
\hline $\begin{array}{l}\text { Varia } \\
\text { bel }\end{array}$ & Analisis & $\begin{array}{l}\text { Kebutuhan } \\
\text { Kedepan }\end{array}$ \\
\hline $\begin{array}{l}\text { Pening } \\
\text { katan } \\
\text { penge } \\
\text { ndalia } \\
\mathrm{n} \\
\text { sistem }\end{array}$ & $\begin{array}{l}\text { Pengendalian } \\
\text { sistem yang } \\
\text { dilakukan oleh } \\
\text { website Versaillus } \\
\text { telah dilakukan } \\
\text { oleh admin. Akan } \\
\text { tetapi, kurangnya } \\
\text { pengendalian } \\
\text { informasi/data } \\
\text { yang dilakukan } \\
\text { admin karena } \\
\text { kurangnya user } \\
\text { yang berkunjung. } \\
\text { Admin juga selalu } \\
\text { mengecek sistem } \\
\text { apakah ada } \\
\text { kecacatan pada } \\
\text { sistem atau tidak. } \\
\text { Untuk web berjenis } \\
\text { wiki, }\end{array}$ & $\begin{array}{l}\text { Meningkatkan } \\
\text { kualitas website } \\
\text { Versaillus agar } \\
\text { lebih } \\
\text { banyaknya } \\
\text { pegunjung. } \\
\text { Admin dan } \\
\text { user juga harus } \\
\text { membuat } \\
\text { website } \\
\text { Versaillus } \\
\text { dengan sistem } \\
\text { dan tombol- } \\
\text { tombol yang } \\
\text { lebih baik lagi } \\
\text { agar website } \\
\text { tersebut } \\
\text { menjadi lebih } \\
\text { ramai. }\end{array}$ \\
\hline
\end{tabular}

Pada variabel efficiency terdapat 3 indikator yang saling mempengaruhi, diantaranya adalah sebagai berikut : efisiensi SDM, waktu dan pekerjaan, serta biaya. Pengukuran variabel efficiency ini didapatkan melalui pengolahan data dari hasil wawancara yang dilakukan. Wawancara yang dilaksanakan tersebut dilakukan dengan master admin dari website tersebut. Hasil dari pengolahan data wawancara mengenai efficiency tersebut akan dipaparkan pada Tabel 5 dilaksanakan dengan melakukan wawancara dengan pemilik website.

Tabel 5 Analisis efficiency

\begin{tabular}{|l|l|l|}
\hline Variabel & Analisis & $\begin{array}{l}\text { Kebutuhan } \\
\text { Kedepan }\end{array}$ \\
\hline SDM & $\begin{array}{l}\text { Sudah ada admin } \\
\text { khusus yang } \\
\text { bertugas untuk } \\
\text { mengelola data } \\
\text { dan informasi } \\
\text { yang ada pada } \\
\text { website. }\end{array}$ & $\begin{array}{l}\text { Meningkatkan } \\
\text { kinerja admin } \\
\text { agar website } \\
\text { tersusun rapi } \\
\text { dan terpercaya } \\
\text { informasinya. } \\
\text { Menambahkan } \\
\text { juga tim } \\
\text { design/admin } \\
\text { lainnya untuk } \\
\text { membantu } \\
\text { meningkatkan } \\
\text { kinerja website } \\
\text { Versaillus. }\end{array}$ \\
\hline & & Penyimpanan \\
\hline Efisiensi & Keseluruhan & \\
\hline
\end{tabular}

\begin{tabular}{|l|l|l|}
\hline $\begin{array}{l}\text { waktu } \\
\text { dan } \\
\text { pekerjaan }\end{array}$ & $\begin{array}{l}\text { data dari awal } \\
\text { hingga akhir } \\
\text { tersimpan dalam } \\
\text { database. }\end{array}$ & $\begin{array}{l}\text { data dalam } \\
\text { database } \\
\text { terarsip dengan } \\
\text { baik dan } \\
\text { teratur agar } \\
\text { memudahkan } \\
\text { dalam } \\
\text { pencarian } \\
\text { histori. }\end{array}$ \\
\hline $\begin{array}{l}\text { Efisiensi } \\
\text { biaya }\end{array}$ & $\begin{array}{l}\text { Versaillus } \\
\text { menggunakan } \\
\text { website gratis } \\
\text { pada } \\
\text { 000webhostapp. } \\
\text { com, karena } \\
\text { gratis maka } \\
\text { tempat hosting } \\
\text { tersebut kurang } \\
\text { maksimal } \\
\text { kecepatan dan } \\
\text { kinerjanya. }\end{array}$ & $\begin{array}{l}\text { Menuah domain } \\
\text { sendiri. } \\
\text { membun } \\
\text { biaya, kinerja } \\
\text { website akan } \\
\text { menjadi lebih } \\
\text { baik untuk } \\
\text { kedepannya. }\end{array}$ \\
\hline
\end{tabular}

Pada variabel service terdapat 2 indikator yang saling mempengaruhi, diantaranya adalah sebagai berikut : ragam informasi dan prosedur untuk mendapatkan informasi. Pengukuran variabel service ini didapatkan melalui pengolahan data dari hasil wawancara yang dilakukan. Wawancara yang dilaksanakan tersebut dilakukan dengan master admin dari website tersebut. Hasil dari pengolahan data wawancara mengenai service tersebut akan dipaparkan pada Tabel 6 dilaksanakan dengan melakukan wawancara dengan pemilik website.

Tabel 6 Analisis Service

\begin{tabular}{|c|c|c|}
\hline Variabel & Analisis & $\begin{array}{l}\text { Kebutuhan } \\
\text { Kedepan }\end{array}$ \\
\hline $\begin{array}{l}\text { Ragam } \\
\text { informasi }\end{array}$ & $\begin{array}{l}\text { Informasi } \\
\text { yang } \\
\text { disajikan } \\
\text { yaitu berupa } \\
\text { konten- } \\
\text { konten mobile } \\
\text { legends. }\end{array}$ & $\begin{array}{l}\text { Menambahkan } \\
\text { beberapa } \\
\text { informasi lainnya } \\
\text { agar website } \\
\text { tersebut menjadi } \\
\text { lebih menarik. } \\
\text { Pengunjung yang } \\
\text { datang akan } \\
\text { merasa bosan jika } \\
\text { informasi yang } \\
\text { diberikan hanya } \\
\text { berisikan konten } \\
\text { mobile legends. } \\
\text { Dibutuhkan } \\
\text { improvisasi } \\
\text { informasi lebih } \\
\text { mendalam agar }\end{array}$ \\
\hline
\end{tabular}




\begin{tabular}{|c|c|c|}
\hline & & $\begin{array}{l}\text { lebih menarik } \\
\text { pengunjung. }\end{array}$ \\
\hline $\begin{array}{l}\text { Prosedur } \\
\text { untuk } \\
\text { mendapat } \\
\text { kan } \\
\text { informasi }\end{array}$ & $\begin{array}{l}\text { Website } \\
\text { Versaillus } \\
\text { mengambil } \\
\text { informasi } \\
\text { langsung dari } \\
\text { website resmi } \\
\text { Mobile } \\
\text { legend. }\end{array}$ & $\begin{array}{l}\text { Memperluas } \\
\text { sumber informasi, } \\
\text { semakin luas } \\
\text { sumber informasi } \\
\text { semakin pula } \\
\text { banyaknya konten } \\
\text { konten yang aka } \\
\text { nada pada website } \\
\text { Versaillus. }\end{array}$ \\
\hline
\end{tabular}

\section{KESIMPULAN}

Berdasarkan penelitian diatas dapat diambil kesimpulan sebagai berikut:

1. Penelitian ini telah mendapatkan hasil dari variabel-variabel yang ada pada PIECES, yang pertama yaitu performance, sudah baiknya kinerja yang ada pada website tersebut. Akan tetapi, kurangnya response time yang dimiliki oleh web Versaillus karena response pada web tersebut sangatlah lama.

2. Pada variabel Informance, informasi yang diberikan oleh website ini sangatlah cukup. Akan tetapi, kurangnya variasi yang diberikan dan kurangnya ketepatan waktu. Versaillus juga belum menjalankan tugasnya sebagai website wiki.

3. Pada variabel economy, Versaillus tidak membutuhkan biaya dalam pembuatan website ini sehingga berdampak pada response time web tersebut.

4. Pada variabel control, Versaillus belum menempatkan dirinya sebagai website wiki. Dikarenakan kurangnya pengunjung, admin hanya menambahkan informasi dan datanya sendiri. Admin belum bisa mengedit apa yang user tambahkan.

5. Pada variabel efficiency, Versaillus telah menyediakan semua kebutuhan penyimpanan data ke database, dan sudah adanya keefisienan biaya dan waktu pada website Versaillus.

6. Pada variabel service, Versaillus telah menyediakan informasi yang tepat sesuai dengan topik website tersebut. Versaillus juga telah meyakinkan bahwa informasi yang diambil dapa t terpercaya.

\section{DAFTAR PUSTAKA}

Adiguna, A. R., Saputra, M. C. dan Pradana, F. 2018. Analisis dan Perancangan Sistem Informasi Manajemen Gudang pada PT Mitra Pinasthika Mulia Surabaya. Surabaya : Jurnal Pengembangan Teknologi Informasi dan Ilmu Komputer.

Andarwati, S. R. dan Sankarto, B. S. 2005. Pemenuhan Kepuasan Penggunaan Internet Oleh Peneliti Badan LITBANG Pertanian di Bogor, Jurnal Perpustakaan Pertanian, vol. 14, Nomor 1.

Andry, J. F. 2016. Performance Measurement of Information Technology Governance: A Case Study, Jurnal Sistem Informasi (Journal of Information Systems). Vol. 12, No.2. Pp. 56-62.

dunia-online. http://www.duniaonline.net/article/mengenal_jenisjenis_ website_berdasarkan_fungsinya.

Diakses pada : 20 Maret 2018

Fauzi, Moch Farid. 2017. Rancang Sistem Direktori Berkas Arsip Siswa Sekolah Dasar. Yogyakarta : Jurnal Ilmiah DASI Vol. 18. No. 4 Desember 2017, hlm. 6-12.

KBBI.

https://kbbi.kemdikbud.go.id/entri/anali sis. Diakses pada : 20 Maret 2018

Hastanti, R. P., Wardati, I. U. dan Purnama, B. E. 2013. Sistem Penjualan Berbasis Web (E-Commerce) Pada Tata Distro Kabupaten Pacitan. Pacitan: IJCSS Indonesian Jurnal on Computer Science

Husni, M. 2008. Analisis Website Sekolah Tinggi Manajemen Informatika dan Komputer Pradnya Paramita Malang (www.pradnya.ac.id) Berdasarkan Segi Usability, Visualization, Functionality dan Accesibility. Malang: Jurnal Dinamika Dotcom Vol. 4 No. 1

Nugroho, N. T. 2016. Pengaruh Penggunaan Teknologi Informasi Terhadap Kinerja Karyawan. Surakarta: Duta.com ISSN : 2086-9436 Volume 11 Nomor 1 
Rahmi, Alfie Nur. 2017. Analisis PIECES Sistem Tracer Study Online Berbasis Website di Universitas AMIKOM Yogyakarta. Yogyakarta : Jurnal Ilmiah DASI Vol. 18. No. 2. Hlm.37-41.

Supriyatna, A. 2015. Analisis dan Evaluasi Kepuasan Pengguna Sistem Informasi Perpustakaan dengan Menggunakan Metode Pieces Framework. Karawang : Jurnal Pilar Nusa Mandiri Volume XI, No.1.

Whitten. J. L. dan Bentley, L. 2007. System Analysis \& Design Methods Seventh Edition. New York, USA : McGrawHill.

Yunus, M. 2009. Analisis dan Perancangan Sistem Informasi Pelayanan Administrasi Desa Berbasis Client Server di Desa Kaliurang. Purwokerto : Jurnal Telematika Vol. 2 No. 2 Agustus 2009. 